\title{
BMJ Open Effect of meteorological factors and air pollutants on fractures: a nationwide population-based ecological study
}

\author{
Taewook Kang, ${ }^{1}$ Jinwook Hong, ${ }^{2}$ Munkhzul Radnaabaatar, ${ }^{2}$ Si Young Park, ${ }^{1}$ \\ Jaehun Jung (D) 2,3
}

To cite: Kang T, Hong J, Radnaabaatar M, et al. Effect of meteorological factors and air pollutants on fractures: a nationwide population-based ecological study. BMJ Open 2021;11:e047000. doi:10.1136/ bmjopen-2020-047000

- Prepublication history and additional supplemental material for this paper are available online. To view these files, please visit the journal online (http://dx.doi.org/10.1136/ bmjopen-2020-047000)

TK and JH contributed equally.

Received 16 November 2020 Accepted 27 May 2021

Check for updates

(c) Author(s) (or their employer(s)) 2021. Re-use permitted under CC BY-NC. No commercial re-use. See rights and permissions. Published by BMJ.

${ }^{1}$ Department of Orthopedics, Korea University College of Medicine and School of Medicine, Seoul, South Korea ${ }^{2}$ Artificial Intelligence and Big-Data Convergence Center, Gachon University Gil Medical Center, Incheon, South Korea ${ }^{3}$ Department of Preventive Medicine, Gachon University College of Medicine, Incheon, South Korea

Correspondence to Dr Jaehun Jung; eastside1st@gmail.com and Dr Si Young Park; drspine90@kumc.or.kr

\section{ABSTRACT}

Objective To determine the association of meteorological factors and air pollutants (MFAPs) with fracture and to estimate the effect size/time lag.

Design This is a nationwide population-based ecological study from 2008 to 2017.

Setting Eight large metropolitan areas in Korea.

Participants of 8093820 patients with fractures reported in the Korea National Health Insurance database, 2129955 were analysed after the data set containing patient data (age, sex and site of fractures) were merged with MFAPs. Data on meteorological factors were obtained from the National Climate Data Center of the Korea Meteorological Administration. Additionally, data on air pollutants (atmospheric particulate matter $\leq 2.5 \mu \mathrm{m}$ in diameter $\left(\mathrm{PM}_{2.5}\right), \mathrm{PM}_{10}$, ozone, nitrogen dioxide, sulfur dioxide and carbon monoxide) were obtained from the Air Korea database.

Primary and secondary outcome measures We hypothesised that there would be an association between MFAPs and the incidence of fracture. A generalised additive model was used while factoring in the non-linear relationship between MFAPs and fractures as well as a time lag $\leq 7$ days. Multivariate analysis was performed. Backward elimination with an Akaike information criterion was used to fit the multivariate model.

Results Overall, in eight urban areas, 2129955 patients with fractures were finally analysed. These included 370 344, 187 370, 173 100, 140 358, 246 775, 6501, 228 346, 57183 and 719978 patients with hip, knee, shoulder, elbow, wrist, hand, ankle, foot and spine fractures, respectively. Various MFAPs (average temperature, daily rain, wind speed, daily snow and $\mathrm{PM}_{2.5}$ ) showed significant association with fractures, with positive correlations at time lags 7, 5-7, 5-7, 3-7 and 6-7 days, respectively. Conclusions Various MFAPs could affect the occurrence of fractures. The average temperature, daily rain, wind speed, daily snow and $\mathrm{PM}_{2.5}$ were most closely associated with fracture. Thus, improved public awareness on these MFAPs is required for clinical prevention and management of fractures.

\section{INTRODUCTION}

Fractures are common globally, with reported increasing incidence, and are major public health issues, with a heavy burden on health resources. $^{1-3}$ The annual global number of

\section{Strengths and limitations of this study}

The study's main strength is that it is the first to investigate the relationship between various meteorological factors and air pollutants (MFAPs) and fractures.

The study has a sample size of 2129 955, much larger than that of the majority of other studies.

- The limitations are that the study sampled patients who lived in major metropolitan cities and that individual MFAP exposure levels were not evaluated.

- Individual risk factors could not be covered in the analysis.

fractures is expected to increase due to ageing population. ${ }^{4}$ In elderly populations, fractures can not only cause temporary dysfunction but also mortality. ${ }^{2} 5$ Advances in surgical techniques and postoperative care have led to lower morbidity and mortality. However, attention has recently turned towards the prevention of fractures. Understanding the circumstances surrounding the occurrence of fractures may provide important information about when and why these injuries occur and may improve prevention.

The relationship between meteorological factors and air pollutants (MFAPs) and their impact on the incidence of fracture has been the subject of many studies; most of which reported that more fractures occur during the winter. ${ }^{6}$ Several hypotheses have been proposed to explain this association. One hypothesis suggests that MFAPs influence the incidence of fracture through bone metabolism effects. Reduced exposure to ultraviolet radiation may result in reduced vitamin D synthesis, thereby resulting in vitamin D and parathyroid hormone level changes. ${ }^{8}$ It affects bone mineral density (BMD) and muscle strength, which can affect mobility and resistance to falls. ${ }^{9}$ However, these effects on bone metabolism are long-term impacts of MFAPs. $^{10}$ 
Other hypotheses are based on the short-term relationship of MFAPs with the incidence of fracture. Increased risk of falling depends on weather conditions due to slippery surfaces. ${ }^{11}$ Freezing temperatures, rain, snow and ice may increase the risk of slipping due to the conditions underfoot, and frequent falling is a known risk factor for fractures. ${ }^{12}{ }^{13}$ In low temperatures, there is an impaired thermoregulation, hypothermia and consequent motor coordination deficits that predispose the elderly to falls, ${ }^{14}$ and there is an increased risk of falls due to clumsiness in movements. These can explain the many occurrences of fractures, indoors and outdoors. ${ }^{15}$ Increased risk of falls can also be due to reduced visual acuity. ${ }^{16}$ The presence of haze is associated with increased incidence of fracture. In foggy weather, air pollutants (dust, ash, clay, sand or ambient air pollutants) are suspended in the atmosphere. ${ }^{17}$

However, most previous studies focused only on hip fracture or total fractures, without the discrimination of the sites of fractures, specific age groups, and the size and location of hospitals. ${ }^{1019}$ There are also insufficient nationwide population-based data. Although previous studies provided data on risk factors for fractures and possible preventive measures, risk factors, age-specific incidence and prognoses may differ depending on the site of fracture. Therefore, it is necessary to determine the association between MFAPs and the occurrence of fractures by fracture site. ${ }^{52021}$

These hypotheses could help in explaining the results of the association between MFAPs and fracture. Understanding the association between MFAPs and the incidence of fracture may lead to improved risk management and development of appropriate interventions. Thus, this study aimed to determine the association between MFAPs and fracture occurrence and to estimate their effect size and lag time.

\section{MATERIALS AND METHODS \\ Data acquisition}

It should be mentioned that the study methodology was based on the authors' previous study. ${ }^{22}$ Records of patients with fractures were provided by the National Health Insurance Service (NHIS), a government-affiliated agency in Korea. We retrieved clinical data on bone fractures for both inpatients and outpatients between 2008 and 2017. The sites of bone fractures were according to the International Classification of Diseases, Tenth Revision, Clinical Modification codes, with the following surgical codes: hip (S72.0-S72.3 and S72.7-S72.9), knee (S72.4 and S82.0-S82.2), shoulder (S42.0-S42.3), elbow (S42.4, S52.0-S52.4 and S52.7-S52.9), wrist (S52.5-S52.6), hand (S62 and T10), ankle (S82.3 and S82.5-S82.6), foot (S92 and T12) and spine (S32.0-S32.2, S32.7-S32.8, S22.0S22.1 and T08). During the study period (2008-2017), we collected 8093820 diagnoses of patients with bone fractures and extracted data from major metropolitan areas, including Seoul, Inchon, Daejeon, Gwangju, Daegu,
Ulsan, Busan and Jeju in Korea. The overall number of patients with fractures in eight urban areas was 2129955 after the data set containing patient data were merged with MFAPs. Data on the general meteorological factors were obtained from the Korea Meteorological Administration National Climate Data Center, while data on air pollutants, such as particulate matter, carbon monoxide and ozone, were from Air Korea, during the same period.

\section{Patient and public involvement}

Patients and the public were not involved in the study.

\section{Statistical analysis}

Statistical analyses were conducted in SAS V.9.4 for Windows. The results are presented as relative risk ratio with $95 \%$ CI. A p value less than 0.05 was considered significant.

\section{Models}

We performed a time series analysis that mainly used generalised additive Poisson regression model (GAM) to control for trends, seasonality, covariates and day of the week. Meteorological and air pollutant data were used to calculate the daily average, excluding the outliers in pollution variables on the days when the level of particulate matter $\leq 2.5 \mu \mathrm{m}$ in diameter $\left(\mathrm{PM}_{2.5}\right)$ was $>120 \mu \mathrm{m} / \mathrm{m}^{3}$. In the time series analysis, GAM leads to unstable estimates due to autocorrelation between meteorological factors and the sites of bone fractures. Thus, we considered that the time lags until the autocorrelation are 'white noise', shown 7 days after the sites of the bone fracture occurrences. The sum of autocorrelation terms was included as a covariate in GAM. Moreover, we compared the Akaike information criterion (AIC) value among MFAPs for each candidate model using backward elimination for a better fit of the model. Each fracture site had the lowest AIC value when the model included average temperature (AT), daily rain (DR), wind speed (WS), daily snow (DS) and $\mathrm{PM}_{2.5}$.

Our final multivariable model is given as follows:

$\log [\mathrm{E}(\mathrm{Y})]=\alpha_{0}+\mathrm{S}(\mathrm{AT}, \mathrm{df}=9)+\mathrm{S}(\mathrm{DR}, \mathrm{df}=9)+$

$\mathrm{S}(\mathrm{WS}, \mathrm{df}=9)+\mathrm{S}(\mathrm{DS}, \mathrm{df}=9)+\mathrm{S}\left(\mathrm{PM}_{2.5}\right), \mathrm{df}=9$

+ offset $(\log$ (province population $))+\gamma($ day of week $)+$

$\gamma($ year $)+\sum_{1 \leq \theta \leq 7} \mathrm{AR}_{7}$

where $\log [\mathrm{E}(\mathrm{Y})]$ is the logged expected number of the daily fracture occurrences, $\alpha_{0}$ is the intercept, $S$ are the smooth functions of the meteorological factors using natural cubic splines, offset is for the provincial population, and $\gamma$ is the indicator variable for the day of the week and year, while the overall autocorrelation effect can be expressed as $\mathrm{AR}_{1}+\ldots+\mathrm{AR}_{7}$ for 7 lag days.

\section{RESULTS}

From a total of 8093820 cases of fractures identified during the 10-year study period in eight urban areas, 


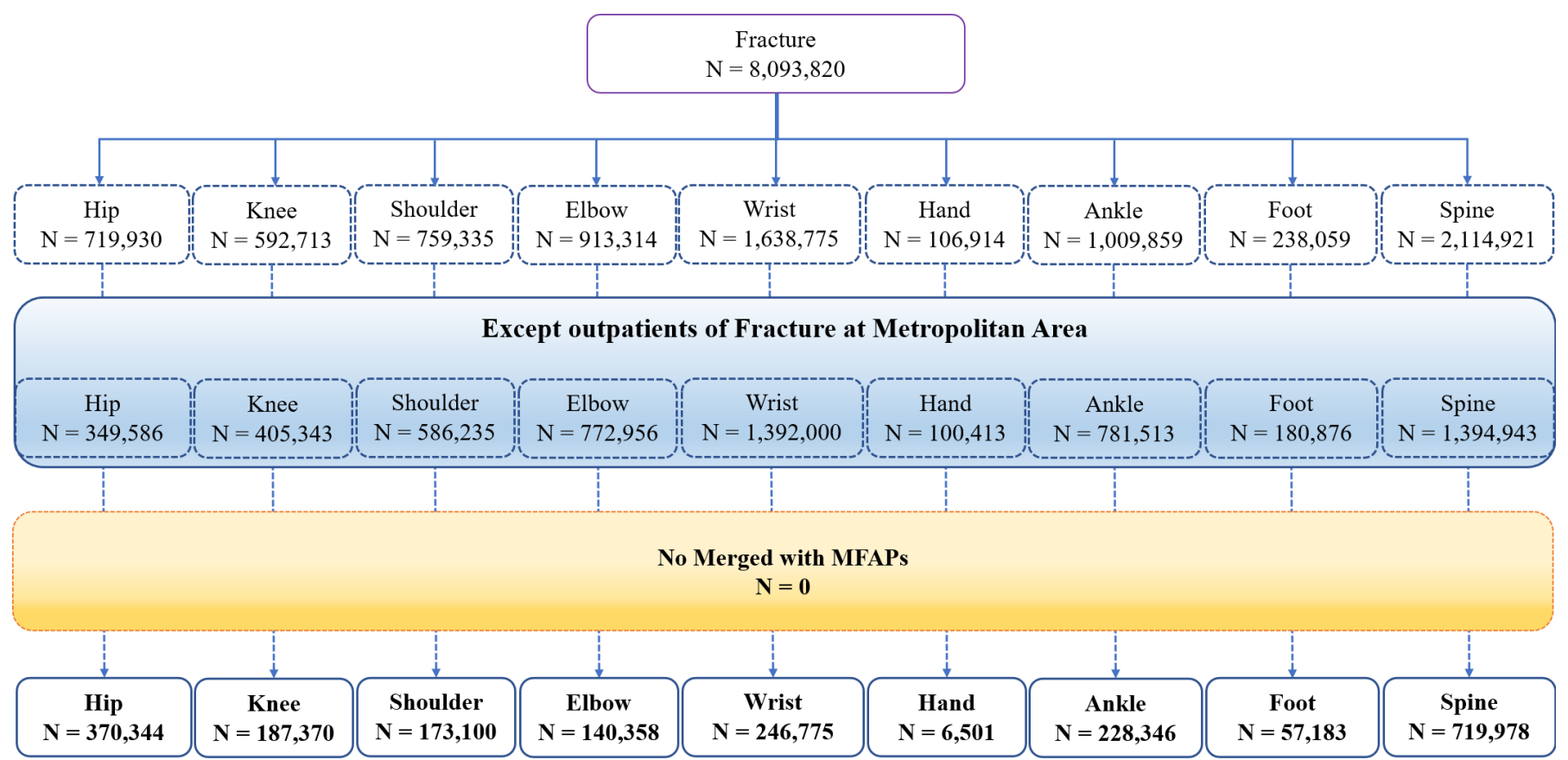

Figure 1 Flow chart of fracture case selection. MFAPs, meteorological factors and air pollutants.

there were 2129955 patients with fractures overall. These included 370 344, 187 370, 173 100, 140 358, 246 775, 6501, 228346,57183 and 719978 patients with hip, knee, shoulder, elbow, wrist, hand, ankle, foot and spine fractures, respectively (figure 1). Of all the fractures, spine $(33.8 \%)$ and hip $(17.4 \%)$ fractures had the largest proportions. The incidence of fractures increased continuously over the study period. Summaries of the number of fractures by age and sex are presented in figure 2 . The mean and SD of MFAP data, by years of exposure to MFAPs, are presented in online supplemental table 1. Among the 13 MFAPs, AT, DR, WS, DS and $\mathrm{PM}_{2.5}$ had the lowest AIC and were selected for further analyses (online supplemental table 2). Models including these five selected MFAPs showed statistically significant association with incidence of fracture.

The predictive models for the incidence of hip fracture using the univariate GAM are shown in figure 3. AT

300,000

250,000

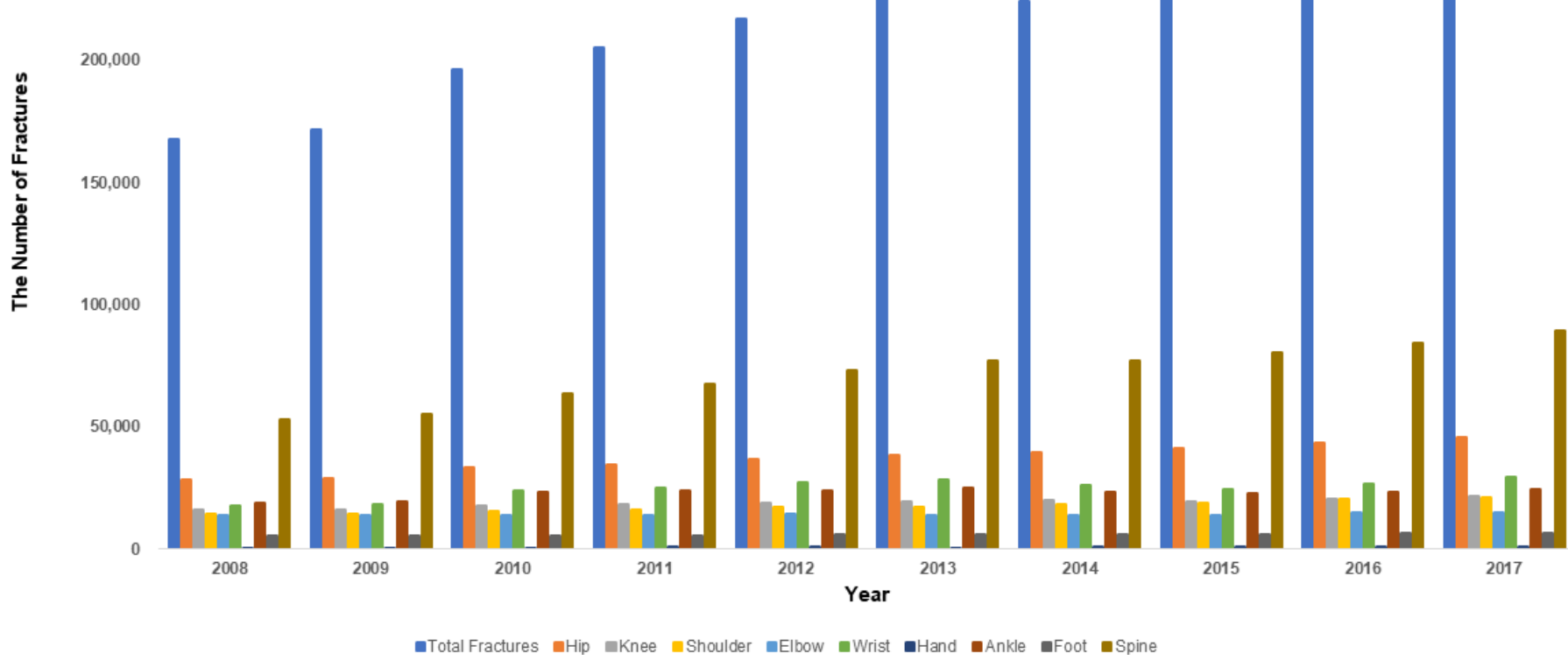

Figure 2 Summary characteristics of the number of fractures. 

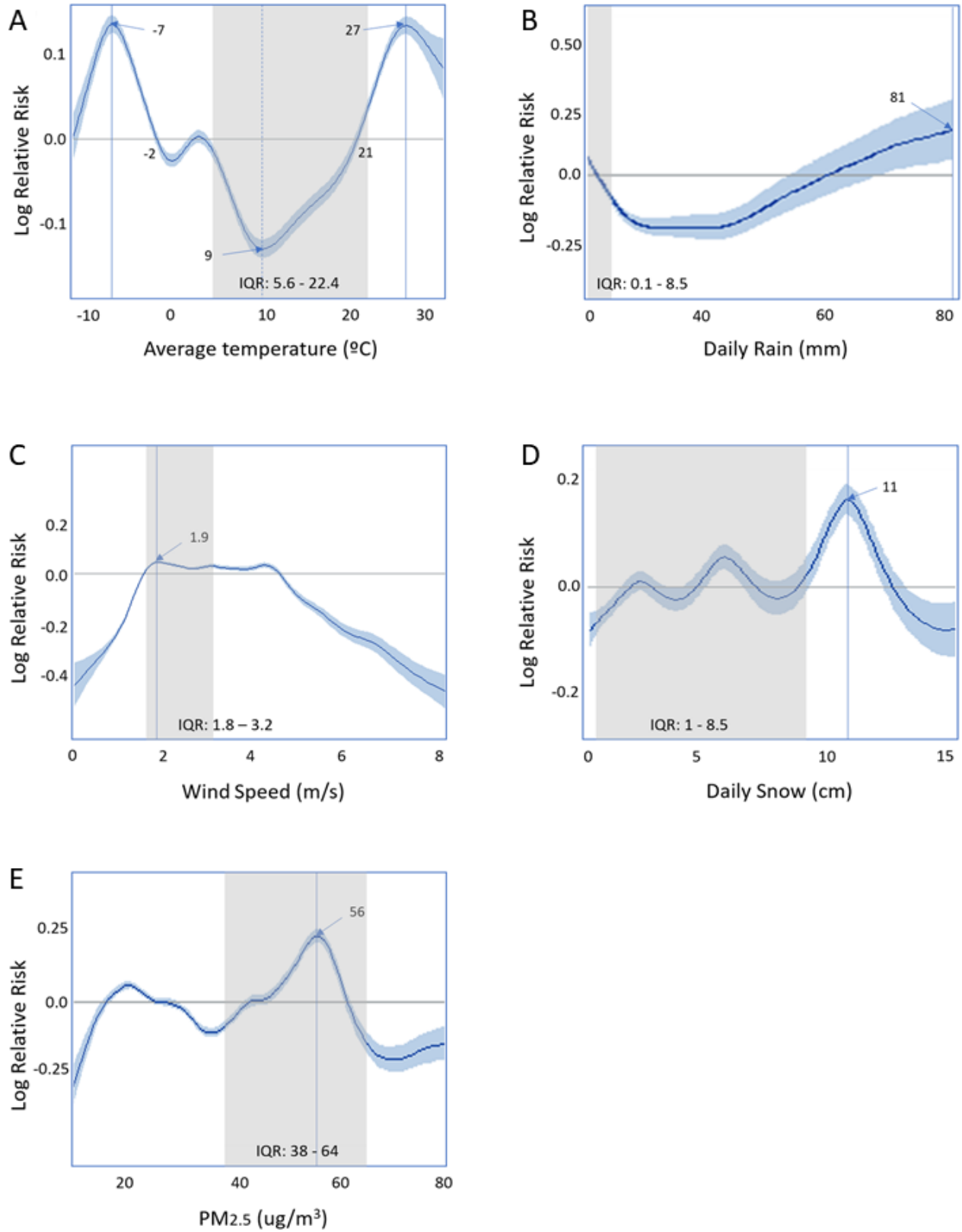

Figure 3 Generalised additive model for the effects of selected meteorological factors on hip fracture incidence: (A) average temperature, (B) daily rain, (C) wind speed, (D) daily snow, and (E) particulate matter $\leq 2.5 \mu m\left(\mathrm{PM}_{2.5}\right)$. The bold line estimates the relative effect sizes for the hip fracture, while the blue area estimates the $95 \% \mathrm{Cl}$. The $\mathrm{x}$-axis represents each selected meteorological factor. The $y$-axis shows the relative effect size for hip fracture.

showed a typical significantly inverted U-shaped correlation $(\mathrm{p}<0.001)$, and fracture was higher in both extremes of AT. A negative risk was seen, from $-2^{\circ} \mathrm{C}$ to $21^{\circ} \mathrm{C}$, with the highest risk at $-7^{\circ} \mathrm{C}$. Furthermore, there was an abrupt increase in the risk of hip fracture at extreme temperatures $\left(<-2^{\circ} \mathrm{C}\right.$ and $\left.>21^{\circ} \mathrm{C}\right)$. The risk associated with rising DR constantly increased with the incidence of hip fractures, with a linear correlation $(\mathrm{p}<0.001)$. DR had negative and positive relative risks at $<60 \mathrm{~mm}$ and $>60 \mathrm{~mm}$, respectively. There was a significant association between hip fracture and WS $(\mathrm{p}<0.001)$, with the highest risk at $1.9 \mathrm{~m} / \mathrm{s}^{2}$. There was a significant association between hip fracture and DS ( $<<0.001)$, with a gradual S-shaped curve. Moreover, there was a significant association between hip fracture and $\mathrm{PM}_{2.5}$ level $(\mathrm{p}<0.001)$. An excess risk was seen in the most frequently observed interval (IQR: 38-64 $\mu \mathrm{g}$ / $\mathrm{m}^{3}$ ).

Fractures at all other sites showed consistent patterns in relation to MFAPs (online supplemental figures 1-8).

For the five selected variables, time lags were analysed using multivariate GAM to identify which prolonged exposure time lag for each variable affects the incidence of fracture (online supplemental table 3). All the five selected MFAPs showed a maximum lag period of 7 days in the impulse response functions analysis, with no further effect beyond this time point. The box plot models of the estimated risk of fracture for the five MFAPs are shown in figure 4. 

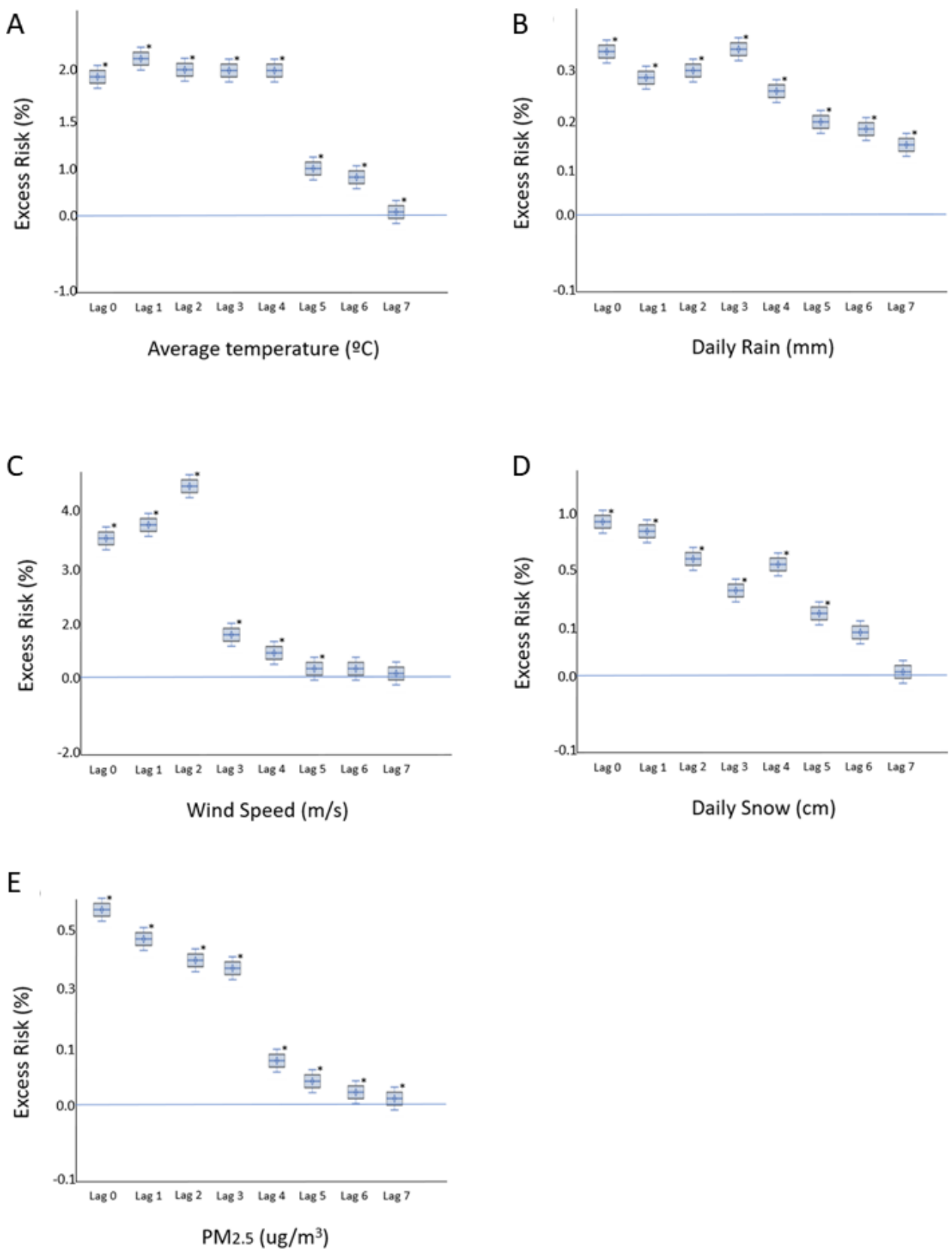

Figure 4 Level of selected meteorological factors and adjusted excess risk of hip fracture: (A) average temperature, (B) daily rain, (C) wind speed, (D) daily snow and (E) particulate matter $\leq 2.5 \mu \mathrm{m}\left(\mathrm{PM}_{2.5}\right)$. The $y$-axis shows the percentage of adjusted excess risk with $95 \% \mathrm{Cl}$. ${ }^{*} \mathrm{P}<0.05$.

Multivariate analyses provided the time lags for the effects of MFAPs on the risk of hip fracture. An increase in AT reflected a significant increase in the risk of hip fracture until 7 days later. The effects of DR, WS, DS and $\mathrm{PM}_{2.5}$ were inversely correlated with lag time, with significantly positive associations 5-7 days before the occurrence of hip fracture.

The results for the time lags also showed consistent patterns in fractures at all other sites (online supplemental figures 9-16).

\section{DISCUSSION}

In our analysis of the nationwide data of the association between fracture and MFAPs, we found AT, DR, WS, DS and $\mathrm{PM}_{25}$ to be closely associated with fracture among various MFAPs. These selected MFAPs were shown to affect fractures up to 7 days later. Our evaluation was based on the short-term relationship between daily variations in different MFAPs and daily incidence of fractures, which occurred due to increased risk of falling from adverse MFAPs. This would explain the significantly positive correlations between fractures and several MFAPs. Our study strengthens the importance of the association of various MFAPs in the incidence of fractures. Fractures at all other sites showed a consistent pattern in relation to MFAPs. 
Globally, fractures are important public health problems due to the related morbidity and mortality, diminished health-related quality of life, and associated costs. Despite the development of effective surgical treatments, the cost of surgery and subsequent disabilities make the prevention of fractures an integral part of any strategy to reduce their impact, especially considering the ageing trend of the population. ${ }^{23}$

Most fractures are not due to a single cause, but from multiple interactions between individuals and the environment. ${ }^{24}$ The reason for the increased number of fractures in adverse MFAPs is not well understood. Recent studies have shown that seasonal patterns observed in fractures may be related to weather patterns such as temperature, snow or ice. ${ }^{1325}$ However, these previous studies reported associations between fractures and weather data driven by seasonal factors, not by daily variability in the incidence of fractures. Moreover, analyses of the relationship between fractures and MFAPs using day as the unit of analysis are very rare in the literature.

Several mechanisms have been proposed for the short-term relationship between the incidence of fractures and various MFAPs. The mechanisms of fractures in each site appeared to be similar because fractures at all other sites showed a consistent pattern in relation to MFAPs.

AT, DR, WS and DS were shown in our study to correlate with a rise in the incidence of fractures. Previous research has shown that slippery conditions greatly enhance the incidence of fractures, explaining this relationship. ${ }^{26} \mathrm{DR}$ had a negative relative risk at $>60 \mathrm{~mm}$ and a relatively positive risk at $<60 \mathrm{~mm}$. This can be explained by the fact that, although people do not go outside, with more rain the road becomes more slippery and the risk of traffic accidents increases. DS showed a gradual S-shaped curve, or an irregular pattern, due to the few days of snow. Jacobsen $e t a t^{6}$ associated MFAPs (snow and ice) with the incidence of hip fractures and observed a significant increase in its incidence, consistent with that with frozen rain. Levy et $a l^{25}$ reported a significant increase in the incidence of hip fractures during days with freezing precipitation. Lau et $a l^{27}$ concluded that AT is a more important independent risk factor for hip fracture.

We found that AT was closely related to a higher incidence of fractures. A possible mechanism is that weather conditions affect activity levels. ${ }^{28}$ Lower temperatures cause blood pressure and haemodynamic changes and decrease dexterity, leading to increased falls and fractures. ${ }^{29}$ They can also reduce physical activity, leading to impaired coordination and consequently bone fragility. ${ }^{30}$ The more cold people feel, the more likely they are to wear extra clothes, which may make them clumsier. Darker and colder weather may increase the number of falls. ${ }^{15}$ Even though many falls occur indoors, changes in activity level due to prevailing weather conditions lead to changes in the risk of falls and fracture rates. These provide plausible explanations for why the rates of fracture are higher on cold days. ${ }^{28}$
Several studies have included wind as an MFAP variable in their analyses. One possible explanation could be that the greater the exposure to wind, the greater the risk of falling. Lau $e t a l^{27}$ found an excessive incidence of hip fractures on more windy days. Mirchandani $e t a l^{30}$ found a significant correlation between WS and the incidence of hip fractures. Jacobsen $e t a t^{6}$ observed an increase in the risk of hip fractures with high WS days. Tenías $e t a l^{23}$ also confirmed increased risk of hip fracture on more windy days.

The mechanisms of the relationship between air pollution and the incidence of fracture are still unclear. Several studies have investigated the possible relationship between air pollution, BMD and fractures. ${ }^{31-33}$ Alvaer $e t$ $a l^{32}$ found an association between osteoporosis, forearm fractures and air pollution, with an inverse association found between BMD and air pollution. Prada $e t a l^{34}$ found an association between long-term exposure to $\mathrm{PM}_{2.5}$ and osteoporosis-related fractures. Chang et $a l^{31}$ showed a tendency of an increased association between air pollution and risk of osteoporosis, suggesting that exposure to air pollution could increase the risk of osteoporosis. Therefore, if reduced bone resistance is the mechanism by which air pollution is involved in hip fracture, there would be no effect in the short term.

What we are actually observing is that air pollution increases the risk of falls. ${ }^{17}$ Reduced visual acuity has long been regarded as a risk factor for fracture. ${ }^{18} 35$ The reduced hours of sunlight and increased air pollution reduce visual acuity, which predisposes to falls and hip fracture. ${ }^{16}$ In a large-scale cohort study, reduced visual acuity increased the likelihood of falls and fractures in the elderly population. ${ }^{18}$ Also, acute exposure to $\mathrm{PM}_{2.5}$ can stimulate the autonomic nervous system (ANS), increasing the risk of arrhythmia, orthostasis and syncope ${ }^{36}$ Therefore, $\mathrm{PM}_{2.5}$ exposure has been associated with changes in heart rate in the elderly. ${ }^{37}$ Reduced heart rate variability due to impairment of ANS could increase the risk of falls.

Our observations on the association of MFAPs with fractures can help in developing prevention strategies for fractures. The elevated incidence during winter implies that we should raise awareness on the risk of slippery conditions, and the importance of keeping warm, improving lighting conditions and avoiding use of cumbersome clothing. ${ }^{38}$

There were some limitations to our study. First, we sampled patients who lived in major metropolitan cities. Weather stations are sparsely placed in rural areas; thus, we ruled to exclude rural areas owing to the concern for unreliable data. Second, individual MFAP exposure levels were not evaluated and we assumed that individuals were exposed to identical environments. Therefore, the possibility of ecological fallacy should be noted. Third, individual risk factors such as comorbidities and lifestyle, which would affect fracture occurrence, could not be controlled in the analysis. Fourth, the decision of whether a fracture occurred was dependent only on the diagnostic 
codes; thus, the validity of healthcare claims data diagnosis on fracture is debatable. We included only inpatient records to reduce the possibility of coding inaccuracies in our data set. Painless, undiagnosed and self-resolved fractures were not included, and there may be a difference between the actual incidence of fracture and the onset of symptoms. Fifth, if citizens tend to stay indoors depending on the level of fine dust, potential bias can occur when special weather forecasts are announced, such as by the fine dust warning service. Moreover, discordance between the actual residential areas and weather stations could be found. Finally, the mechanisms underlying the effect of each MFAP on fracture occurrence could not be identified.

However, our study has several strengths. First, this study was the first to investigate the relationship between various MFAPs and fractures. Second, because we used nationallevel NHIS data, we had the advantage of including a sample size of 2129 955, much larger than in the majority of other studies. As a result of the single-payer universal healthcare coverage in Korea, the catchment of fractures was expected to be very high. These facilitated the analyses of a large and credible data set, which is often hard to implement in other countries. Third, we investigated the relationship between all 13 MFAPs portrayed by the Korea Meteorological Administration, and this allowed a plausible review of the real-world influences and interactions of $\mathrm{PM}_{2.5}$ with diverse MFAPs. Fourth, the current study was representative of the capital city and seven other areas in Korea, which could reduce bias by diminishing regionspecific effects such as race, ethnicity, economic level and accessibility to hospitals. Fifth, time series Poisson analysis was used with GAM to consider the interaction among MFAPs in terms of fracture occurrence.

\section{CONCLUSIONS}

In conclusion, we investigated the relationship between MFAPs and fracture based on healthcare claims and data from a meteorological database. AT, DR, WS, DS and $\mathrm{PM}_{2.5}$ were identified as MFAPs that were most closely associated with fracture. These MFAPs maintained influence for a maximum of 7 days. Visualisation of the effect-time association of MFAPs with fracture was possible in the model. In the future, further confirmatory studies and improved public awareness regarding MFAPs that are related to the incidence of fracture are needed for clinical prevention and management of fractures.

Contributors Conception and design: TK, JJ. Collection and assembly of data: JH, JJ. Data analysis and interpretation: TK, JH, JJ. Writing the manuscript: MR, TK, SYP. Final approval of the manuscript: all authors. Accountable for all aspects of the work: all authors.

Funding This study was supported by grants from the Gachon University Gil Medical Center (2019-11). Also this work was supported by the Reseach Program funded by the Korea Disease Control and Prevention Agency(2021-ER1202-00)

Competing interests None declared.

Patient consent for publication Not required.
Ethics approval The study was reviewed and exempted from the requirement of written informed consent by the Institutional Review Board of Gachon University Gil Medical Center (approval number: GCIRB2019-039), which was waived due to the retrospective nature of this study. The study methods were carried out based on the Declaration of Helsinki.

Provenance and peer review Not commissioned; externally peer reviewed.

Data availability statement Data are available upon reasonable request. The data sets generated during and/or analysed during the current study are available from the corresponding author on reasonable request.

Supplemental material This content has been supplied by the author(s). It has not been vetted by BMJ Publishing Group Limited (BMJ) and may not have been peer-reviewed. Any opinions or recommendations discussed are solely those of the author(s) and are not endorsed by BMJ. BMJ disclaims all liability and responsibility arising from any reliance placed on the content. Where the content includes any translated material, BMJ does not warrant the accuracy and reliability of the translations (including but not limited to local regulations, clinical guidelines, terminology, drug names and drug dosages), and is not responsible for any error and/or omissions arising from translation and adaptation or otherwise.

Open access This is an open access article distributed in accordance with the Creative Commons Attribution Non Commercial (CC BY-NC 4.0) license, which permits others to distribute, remix, adapt, build upon this work non-commercially, and license their derivative works on different terms, provided the original work is properly cited, appropriate credit is given, any changes made indicated, and the use is non-commercial. See: http://creativecommons.org/licenses/by-nc/4.0/.

ORCID iD

Jaehun Jung http://orcid.org/0000-0002-4856-3668

\section{REFERENCES}

1 Lee Y-K, Kim JW, Lee MH, et al. Trend in the age-adjusted incidence of hip fractures in South Korea: systematic review. Clin Orthop Surg 2017;9:420-3.

2 Compston JE, McClung MR, Leslie WD. Osteoporosis. Lancet 2019;393:364-76.

3 Braithwaite RS, Col NF, Wong JB. Estimating hip fracture morbidity, mortality and costs. J Am Geriatr Soc 2003;51:364-70.

4 Cummings SR, Melton LJ. Epidemiology and outcomes of osteoporotic fractures. Lancet 2002;359:1761-7.

5 Abrahamsen B, van Staa T, Ariely R, et al. Excess mortality following hip fracture: a systematic epidemiological review. Osteoporos Int 2009;20:1633-50.

6 Jacobsen SJ, Sargent DJ, Atkinson EJ, et al. Population-Based study of the contribution of weather to hip fracture seasonality. Am J Epidemiol 1995;141:79-83.

7 Caniggia M, Morreale P. Epidemiology of hip fractures in Siena, Italy, 1975-1985. Clin Orthop Relat Res 1989:131-8.

8 Pasco JA, Henry MJ, Kotowicz MA, et al. Seasonal periodicity of serum vitamin $\mathrm{D}$ and parathyroid hormone, bone resorption, and fractures: the Geelong osteoporosis study. J Bone Miner Res 2004;19:752-8.

9 Dukas L, Staehelin HB, Schacht E, et al. Better functional mobility in community-dwelling elderly is related to D-hormone serum levels and to daily calcium intake. J Nutr Health Aging 2005;9:347-51.

10 Kung AWC, Lee K-K, Ho AY, et al. Ten-Year risk of osteoporotic fractures in postmenopausal Chinese women according to clinical risk factors and BMD T-scores: a prospective study. J Bone Miner Res 2007;22:1080-7.

11 Román Ortiz C, Tenías JM, Estarlich M, et al. Systematic review of the association between climate and hip fractures. Int $\mathrm{J}$ Biometeorol 2015;59:1511-22.

12 Burger $\mathrm{H}$, de Laet $\mathrm{CE}$, Weel AE, et al. Added value of bone mineral density in hip fracture risk scores. Bone 1999;25:369-74.

13 Bulajic-Kopjar M. Seasonal variations in incidence of fractures among elderly people. Inj Prev 2000;6:16-19.

14 Collins KJ, Easton JC, Belfield-Smith $\mathrm{H}$, et al. Effects of age on body temperature and blood pressure in cold environments. Clin Sci 1985;69:465-70.

15 Douglas S, Bunyan A, Chiu KH, et al. Seasonal variation of hip fracture at three latitudes. Injury 2000;31:11-19.

16 Jacobsen SJ, Goldberg J, Miles TP, et al. Seasonal variation in the incidence of hip fracture among white persons aged 65 years and older in the United States, 1984-1987. Am J Epidemiol 1991;133:996-1004. 
17 Mazzucchelli R, Crespi Villarias N, Perez Fernandez E, et al. ShortTerm association between outdoor air pollution and osteoporotic hip fracture. Osteoporos Int 2018;29:2231-41.

18 Hong T, Mitchell P, Burlutsky G, et al. Visual impairment and the incidence of falls and fractures among older people: longitudinal findings from the blue Mountains eye study. Invest Ophthalmol Vis Sci 2014;55:7589-93.

19 Cummings SR, Nevitt MC, Browner WS, et al. Risk factors for hip fracture in white women. N Engl J Med Overseas Ed 1995;332:767-73.

20 Nilsson M, Eriksson J, Larsson B, et al. Fall risk assessment predicts fall-related injury, hip fracture, and head injury in older adults. $J \mathrm{Am}$ Geriatr Soc 2016;64:2242-50.

21 Baron JA, Karagas M, Barrett J, et al. Basic epidemiology of fractures of the upper and lower limb among Americans over 65 years of age. Epidemiology 1996;7:612-8.

$22 \mathrm{Kim} \mathrm{J-H}$, Hong J, Jung J, et al. Effect of meteorological factors and air pollutants on out-of-hospital cardiac arrests: a time series analysis. Heart 2020;106:1218-27.

23 Tenías JM, Estarlich M, Fuentes-Leonarte V, et al. Short-Term relationship between Meteorological variables and hip fractures: an analysis carried out in a health area of the autonomous region of Valencia, Spain (1996-2005). Bone 2009;45:794-8.

24 Tinetti ME. Clinical practice. preventing falls in elderly persons. $N$ Engl J Med 2003;348:42-9.

25 Levy AR, Bensimon DR, Mayo NE, et al. Inclement weather and the risk of hip fracture. Epidemiology 1998;9:172-7.

26 Campbell AJ, Spears GF, Borrie MJ, et al. Falls, elderly women and the cold. Gerontology 1988;34:205-8.

27 Lau EM, Gillespie BG, Valenti L, et al. The seasonality of hip fracture and its relationship with weather conditions in New South Wales. Aust J Public Health 1995;19:76-80.
28 Turner RM, Hayen A, Dunsmuir WTM, et al. Air temperature and the incidence of fall-related hip fracture hospitalisations in older people. Osteoporos Int 2011;22:1183-9.

29 Riley MW, Cochran DJ. Dexterity performance and reduced ambient temperature. Hum Factors 1984;26:207-14.

30 Mirchandani S, Aharonoff GB, Hiebert R, et al. The effects of weather and seasonality on hip fracture incidence in older adults. Orthopedics 2005;28:149-55.

31 Chang $\mathrm{K}-\mathrm{H}$, Chang $\mathrm{M}-\mathrm{Y}$, Muo $\mathrm{C}-\mathrm{H}$, et al. Exposure to air pollution increases the risk of osteoporosis: a nationwide longitudinal study. Medicine 2015;94:e733.

32 Alvaer K, Meyer HE, Falch JA, et al. Outdoor air pollution and bone mineral density in elderly men - the Oslo Health Study. Osteoporos Int 2007;18:1669-74.

33 Alver K, Meyer HE, Falch JA, et al. Outdoor air pollution, bone density and self-reported forearm fracture: the Oslo health study. Osteoporos Int 2010;21:1751-60.

34 Prada D, Zhong J, Colicino E, et al. Association of air particulate pollution with bone loss over time and bone fracture risk: analysis of data from two independent studies. Lancet Planet Health 2017:1:e337-47.

35 Luukinen $\mathrm{H}$, Koski K, Laippala $\mathrm{P}$, et al. Factors predicting fractures during falling impacts among home-dwelling older adults. J Am Geriatr Soc 1997;45:1302-9.

36 Liao D, Duan Y, Whitsel EA, et al. Association of higher levels of ambient criteria pollutants with impaired cardiac autonomic control: a population-based study. Am J Epidemiol 2004;159:768-77.

37 Devlin RB, Ghio AJ, Kehrl H, et al. Elderly humans exposed to concentrated air pollution particles have decreased heart rate variability. Eur Respir J Supp/ 2003;40:76S-80.

38 Koren L, Barak A, Norman D, et al. Effect of seasonality, weather and holidays on the incidence of proximal hip fracture. Isr Med Assoc J 2014;16:299-302. 